\title{
On-line Management of Text Production from Pictures: A Comparison between Fifth Graders and Undergraduate Students
}

\author{
Elise Drijbooms ${ }^{1,4}$, Margriet A. Groen ${ }^{2}$, Denis Alamargot ${ }^{3}, \&$ Ludo Verhoeven $^{4}$ \\ ${ }^{1}$ Katholieke Universiteit Leuven Campus Brussels, Language and Education - Belgium; Behavioural Science \\ Institute, Radboud Universiteit Nijmegen - the Netherlands \\ 2 Department of Psychology, Lancaster University, Bailrigg, Lancaster, LA1 4YF- United Kingdom \\ ${ }^{3}$ Laboratoire CHArt (Cognitions Humaine \& Artificielle) EA 4004 - ESPE de l'Académie de Créteil \\ - Université Paris-Est Créteil (UPEC) - France \\ ${ }^{4}$ Behavioural Science Institute, Radboud Universiteit Nijmegen - the Netherlands
}

Author note: Correspondence concerning this article should be addressed to Elise Drijbooms, Katholieke Universiteit Leuven Campus Brussels, Language and Education, Warmoesberg 26, 1000 Brussels, Belgium - emailaddress: elise.drijbooms@kuleuven.be

\section{Acknowledgements}

This research was funded by and conducted at the Behavioural Science Institute, Radboud University Nijmegen, the Netherlands. 
This study was designed to enhance our understanding of the on-line management of writing processes by two groups of writers with a different level of expertise, and to explore the impact of this on-line management on text quality.To this aim, fifth graders (mean age: 10.5 years) and undergraduate students (mean age: 22.6 years) were asked to compose a narrative from a visual source of images, while their handwriting activity and eye movements were recorded by means of Eye \& Pen software and a digitizing tablet. Results showed that fifth graders and undergraduate students used different strategies to engage in high-level sourcebased text elaboration processes throughout their writing. The main differences concerned the density of source consultation during prewriting, on the one hand, and during pauses, on the other hand. Relationships between these characteristics of on-line management and text quality were minimal in fifth graders, while in undergraduate students, they were more substantial as in the case of syntactic complexity. These findings suggest that with age, the on-line management of writing becomes more closely related to text quality. In line with a capacity view of writing, it is also concluded that the on-line management of writing processes of fifth graders is highly constrained by a lack of fluent text production skills which ultimately affects their text quality. 
Writing a text requires the mastery of a number of low-level (i.e. formulating skills such as handwriting, and spelling) and high-level (i.e. planning and reviewing) writing processes. As all writing processes require more or less cognitive resources of working memory (WM), an efficient management of writing processes within the limits of WM is fundamental to producing good-quality texts (e.g., Breetvelt, van den Bergh, \& Rijlaarsdam, 1994; Levy \& Ransdell, 1995). In contrast to oral language production, relatively little is known about this management of text production. There is accumulating evidence that writing expertise might favor a parallel as opposed to a sequential execution of low- and high-level writing processes, as long as these processes do not exceed WM capacity. This evidence aligns with assumptions of theoretical models of text production and writing development (Bereiter \& Scardamalia, 1987; Berninger \& Swanson, 1994). However, an empirical detailed description of how writers with different levels of expertise coordinate writing processes is lacking. Knowing how exactly writing processes interact could substantially advance our understanding of writing processes and their development. Despite the fact that real-time indicators and eye movements are now increasingly used in writing research and allow for a more detailed and fine-grained analysis of the dynamics of writing, very little research has reverted to such analysis to document the on-line management of text production. Therefore the aim of the present study was to document and compare the on-line management of writing processes of fifth graders (considered here as novices in text production) and undergraduate students (considered here as experts in text production) in a precise and detailed way during narrative composition and explore its relationship to text quality.

According to capacity theory (Just \& Carpenter, 1992; McCutchen, 1996), all writing processes compete for limited cognitive resources in WM. An important consequence of the limited capacity of WM is that an efficient on-line management of the different writing processes is necessary, in order to not exceed WM capacity (McCutchen, 1996). Writers thus have to coordinate the resources allocated to the different processes in writing (Kellogg, 1987; Kieft, Rijlaarsdam, \& van den Bergh, 2008). As such, management should be interpreted as the temporal organization or timing of a writing process within the limits of WM, and reflects the strategies that writers use to cope with the cognitive demands of the writing processes.

One solution to manage cognitive load effectively consists in using a prewriting period i.e. a pause implemented before setting pen to paper - to conceptually plan the text, analyze the demands of the writing task and set goals that will guide text production (Beauvais, Olive, $\&$ Passerault, 2011), such that these processes require less attention during actual writing. 
Prominent novice-expert models of writing (Bereiter \& Scardamalia, Berninger \& Swanson, 1994) assert that this strategy only gradually emerges. In particular, Bereiter and Scardamalia (1987) conceive of the acquisition of writing expertise as a shift in strategies from knowledgetelling in novice writers (i.e., step-by-step, local planning of clear-cut small chunks of information) to knowledge-transforming in more skilled writers (i.e., generating content and organizing ideas prior to writing, and using increasingly complex processing strategies). According to Berninger and Swanson (1994) it is only in the upper elementary grades that planning prior to writing emerges as a strategy, though it generally lasts until the lower secondary grades before prewriting activities start to guide text generation. Spacing out the conceptual component of the writing task through the use of a prewriting pause has proven to have beneficial effects on text quality, both through mental preplanning (Kellogg, 1988; Beauvais et al., 2011), as well as through planning strategies such as outlining (Limpo \& Alves, 2018).

In addition to the key role of prewriting as a strategy for managing cognitive load, the online management of low- and high-level writing processes during actual writing can furthermore be described by distinguishing between periods of parallel processing and sequential processing (van Galen, 1991). The idea underlying this distinction is that high-level writing processes such as lexical access or conceptual processing may be activated in a parallel or in a sequential way with respect to low-level processes of handwriting execution, depending on their cost in terms of cognitive resources. Reaching such a kind of parallel management is only progressive, supposing several years of practices. According to Alamargot and Fayol (2009), being able to manage a parallel engagement of writing processes is subtended by two mechanisms, with one gradually taking over from the other. The automatization of handwriting (execution of the written trace) and formulating (lexical and grammatical spelling) gradually gives way to the parallel installation of more elaborate composition strategies, leading to texts of higher quality. Indeed, according to capacity theory (McCutchen, 1996), the automatization of low-level processes via practice frees up cognitive resources, making them available for "high-level" strategic processes, which can then be fluently activated in parallel with the "low-level", ones (i.e. notion of parallel processing during graphomotor execution - Alamargot, Dansac, Chesnet, \& Fayol, 2007). Failing to be able to carry out a parallel engagement of processes, novices in writing need to dissociate high and low levels of processing by sequentializing the processes (i.e planning the text content without being able to handwrite and spell at the same moment, and then handwriting 
and spelling text without being able to plan the next text content at the same moment) (Olive, 2014). As a consequence, text composition in novices is generally less fluent than in experts, due to the presence of more frequent pauses (i.e. interruption of handwriting for planning, for instance).

These different ways of process coordination adopted by novice versus expert writers aligns with assumptions by prominent, developmental models of writing (Bereiter \& Scardamalia, 1987; Berninger \& Swanson, 1994). According to Berninger and Swanson (1994) handwriting processes become increasingly automatized with age and experience, and particularly after 7 th grade, such that other more high-level writing processes can function more efficiently. This automatization presumably also leaves room for a shift in writing strategies, from knowledge-telling in novice writers to knowledge-transforming in more skilled writers (Bereiter \& Scardamalia, 1987). Alves, Castro, and Olive (2008) and Olive, Alves, and Castro (2009), using direct verbalization and secondary reaction times, demonstrated that in undergraduate students, grammatical and lexical spelling is most frequently activated in parallel with handwriting, because it is the least cognitively demanding process. The importance of automatized handwriting skills for the parallel execution of writing processes was already evidenced in an early study by Chanquoy, Foulin, and Fayol (1990) showing that in expert writers the preparation of one text segment can take place in parallel with the transcription of the previous one. Novice writers, by contrast, are more constrained by their demanding handwriting activities, and therefore forced to sequentialize low- and high-level writing processes. Similarly, when adults have to transcribe text in an unfamiliar style of handwriting, they are no longer able to concurrently activate high-level writing processes, and shift to a more sequential management (Olive \& Piolat, 2002). The way low- and high-level writing processes are coordinated during writing may impact on text quality, with automatization of handwriting playing a fundamental role in this respect. In particular, the think-and-then-write strategy, typical of a more sequential management, text quality may suffer, as there are more opportunities for forgetting ideas or text that have already been prepared but are not yet written down (for a synthesis, see: Olive, 2014; Limpo $\&$ Alves, 2018). Instead, when attention is freed from the demanding low-level writing processes, a thinking-while-writing strategy can be more efficiently implemented. That is, high-level writing processes that are activated in parallel can receive more cognitive resources, and can therefore be more successfully coordinated in WM, ensuring a well-written text (Berninger \& Winn, 2006; Olive, Favart, Beauvais, \& Beauvais, 2009). 
Although existing writing research methodologies (such as dual and triple tasks) have increased our understanding of the on-line management of low- and high-level writing processes, they do not provide the fine-grained detail necessary to reveal the moment-tomoment time course of processes. In particular, they do not inform us about what the writer is doing during prewriting, and during periods of parallel and sequential processing. Knowing how exactly writing processes interact can do much to support and develop theory of writing and writing development. Recently, eye movements have started to be implemented in writing research as they allow for a more fine-grained analysis of the dynamics of writing (e.g., for handwriting: Alamargot, Chesnet, Dansac, \& Ros, 2006; Alamargot, Dansac, Chesnet, \& Fayol, 2007; Alamargot, Plane, Lambert, \& Chesnet, 2010; Alamargot et al., 2015; Alves \& Limpo, 2015; Alves, Limpo, Fidalgo, Carvalhais, Pereira, \& Castro, 2016; Lambert, Alamargot, Larocque, \& Caporossi, 2011; Sita \& Taylor, 2015; For typing: Alves, et al., 2016; Johansson et al., 2010; Nottbusch, 2010; Torrance \& Nottbusch, 2012; Van Waes, Leijten, \& Quinlan, 2010; Wengelin et al., 2009; Torrance, Johansson, Johansson, \& Wengelin, 2015). A combined analysis of handwriting activity (i.e. the varying patterns of handwriting and pauses) and eye movements has proven to be particularly informative in documenting the on-line management of written composition, including parallel and sequential processing. More particularly, while carrying out high-level writing processes such as planning or revising, the eyes move within the task environment, including the text produced so far and any potential documentary sources (Alamargot et al., 2010). Recording the eye movements within the task environment relative to the writer's handwriting activity can therefore provide valuable information about how low- and high-level writing processes are managed. Alamargot, Dansac, Chesnet, and Fayol (2007), for instance, demonstrated that in graduate students writing a procedural text, visual searches on a source (photographs and labels of objects making up a model turbine) or on the text produced so far can take place in parallel with handwriting, for as much as $10 \%$ of the handwriting time. Eye movements are particularly useful to more accurately describe how high-level writing processes operate with respect to the different clues available in the task environment. Alamargot, Caporossi, Chesnet, and Ros (2011) documented how undergraduate students with different levels of WM capacity elaborated a procedural text, based on a documentary source. They found that high WM capacity writers spent more time on the task than low WM capacity writers, reflected in a higher number of and longer fixations on the source, and a higher number of eye 
movement transitions between different parts within the source. Their texts also achieved the communicative goal more efficiently, by using more reader supports. These results were interpreted to reflect high WM writers' ability to strategically activate high-level writing processes during pauses in order to engage in more complex text planning.

To our knowledge, the only study that has looked at the on-line management of written composition comparing writers with different levels of writing expertise by analyzing handwriting activity and eye movements simultaneously is a case study by Alamargot, Plane, Lambert, and Chesnet (2010), carried out with a 7th, 9th, and 12th grader, a graduate student, and a professional writer. Participants were asked to write a text from a documentary source, consisting of the beginning of a narrative. Similar to Alamargot et al. (2011), source consultation was thought to reflect high-level writing processes necessary for text elaboration. It was measured by analyzing the fixation frequency and fixation duration on the source during prewriting, i.e. prior to the first pen stroke, and during composition. The authors referred to these measures as the "density of source reading". Three key findings of the study are worth mentioning: First, the 7th grader stood out on account of her very low density of source reading during prewriting. In particular, the 7th grader was found to frequently pause for brief fixations on the source. The authors interpreted this writing strategy as local planning, characteristic of knowledge-telling (Bereiter \& Scardamalia, 1987). Second, the 12th grader was found to engage in a strategic, overall planning of the text through a dense reading of the source during prewriting, which allowed her to read the source more scantily during composition. Third, across all writers, most source reading took place during pauses, but there was a gradual emergence of more frequent episodes of parallel processing in the graduate student and the professional writer, who regularly engaged in source consultation during handwriting. Furthermore, the general temporal parameters of the writers' writing process revealed an increased speed and fluency, and a reduced mean pause duration, and pause frequency with age. Overall, the authors summarized the trends observed in the study as a gradual automatization of low-level writing processes and a complexification of high-level writing processes between 7 th and 12th grade, and a gradual proceduralization of high-level writing processes, favoring more frequent parallel processing, in the more expert writers. While the results of this study hint at a coherent, developmental timeframe of the on-line management of written composition, they are based on a set of case studies only, and should therefore be replicated in larger samples, including younger writers in elementary school. 


\section{The present study}

The present study had two aims. Firstly, it aimed to document how two groups of writers with different levels of expertise, notably fifth graders and undergraduate students, differ in managing writing processes on-line during the composition of a narrative from a visual source, based on a fine-grained analysis of handwriting activity and eye movements. To this aim, writers' source consultation was analyzed separately for three time frames: during prewriting, during episodes of sequential processing (i.e., when source consultation takes place during pauses), and during episodes of parallel processing (i.e. when source consultation takes place during handwriting). Following previous research (e.g., Alamargot et al., 2010; Alamargot et al., 2011), both the frequency and the density of source consultation were analyzed. We expected fifth graders to engage less in parallel processing than undergraduate students due to the higher constraining role of transcription skills (e.g., Chanquoy et al., 1990; Fayol, 1999; McCutchen, 1996; Olive \& Kellogg, 2002). Furthermore, during prewriting, we expected fifth graders to show a lower fixation density (Alamargot et al., 2010), as a result of their more limited ability to engage in global planning (Bereiter \& Scardamalia, 1987; Chanquoy et al., 1990). During episodes of sequential processing, we expected fifth graders to make more transitions from the text to the source than undergraduate students (Alamargot et al., 2010), in line with their step-by-step composition of the text and their inability to process and retain in memory multiple chunks of information at once (Bereiter \& Scardamalia, 1987). By contrast, we expected undergraduate students to exhibit a higher fixation density, but lower frequency than fifth graders, as a result of their more complex processing strategies (Alamargot et al., 2010; Alamargot et al., 2011; Bereiter \& Scardamalia, 1987; Berninger \& Swanson, 1994; Torrance, 1996). During episodes of parallel processing, we expected undergraduate students to return more frequently from the text to the source, and to show a higher fixation density on the source than fifth graders, as they will be able to sustain their handwriting for longer before accumulated demands of writing processes induce a pause.

Secondly, in order to identify effective writing strategies, the present study also aimed to examine to what extent the characteristics of these writing dynamics are related to text quality. The inclusion of fifth graders and undergraduate students allowed a comparison of writers who span writing stages associated with knowledge-telling and knowledgetransforming (Bereiter \& Scardamalia, 1987). Correlational analyses were used to find out to 
what extent on-line management of writing processes is related to text quality in novice and more expert writers.

We hypothesized to find several relationships between characteristics of on-line management and text quality, in light of the idea that effective writing depends on the writer's ability to coordinate all the different processes involved (Galbraith \& Rijlaarsdam, 1999). It was, for instance, hypothesized that density of source consultation during prewriting would affect text quality (e.g., Beauvais et al., 2011; Beauvais et al., 2012).

Furthermore, differential relationships of on-line management with text quality in the two groups of writers could be expected. In particular in young writers, these strategies of on-line management may result from the way they deal with cognitive demands (Berninger \& Winn, 2006; Olive et al., 2009; Olive, 2014) whereas in more skilled writers they may possibly also result from a more strategic activation of high-level writing processes (e.g., Alamargot et al., 2011).

\section{Method}

\section{Participants}

Thirty-eight undergraduate students and 42 children in fifth grade from two different schools in the Netherlands participated in this study. Children with diagnoses of developmental disorders, such as dyslexia and Attention Deficit (Hyperactivity) Disorder, were excluded from the analyses $(n=8)$. Subsequent analyses were therefore conducted on the data from 38 undergraduate students and 34 children. Education levels of the undergraduate students were bachelor's degree (52\%) and master's degree (48\%). The undergraduates' sample comprised 11 men and 27 women. The undergraduate students had different academic backgrounds: 89\% was drawn from the humanities, and $11 \%$ from the exact sciences. The mean age of the sample was 22.6 years $(S D=3.4)$, with ages ranging from 19 to 36 . The children's sample comprised 18 boys and 16 girls. The mean age of the sample was 10.5 years $(S D=0.8)$, with ages ranging from 9 to 11 years.

\section{Handwritten Composition Task}

The narrative composition task consisted of producing a story from a series of eight images depicting a narrative (Taaltoets Alle Kinderen, TAK; Verhoeven \& Vermeer, 2001). Although the instrument was originally designed for assessing oral narrative skills, the instructions were 
adapted for assessing writing. Throughout the composition task, participants were free to consult the images. The duration of the task was not imposed. Participants were instructed to write their story on two 12-lines columns below the images, and were asked to complete their story by the end of the second column. The exact wording of the writing assignment was: "You will be given eight images depicting a story. The images are put in the right order. Write a story that goes with the images. Look carefully at the images, before starting to write. The images will remain visible throughout the task, so you can consult them as and when you like". Participants were not given the possibility to elaborate a written draft prior to writing. All participants wrote in their first language (Dutch).

\section{Apparatus}

During the composition, eye and handwriting movements were recorded by means of the Eye \& Pen software (Alamargot, Chesnet, Dancas, \& Ros, 2006; Chesnet \& Alamargot, 2005). Participants wrote on a digitizing tablet, a Cintiq 22HD LCD tablet, driven by a computer running the Eye \& Pen software. Eye movements were simultaneously recorded by an Eyelink II head-mounted eye-tracker (S.R. Research Ltd), which equally transmitted the data to the computer running the Eye \& Pen software. The Eyelink II has a sampling frequency of $500 \mathrm{~Hz}$ for monocular (dominant-eye) recording.

The Cintiq 22HD LCD tablet was placed on an adjustable-height table. Participants were asked to stand up while writing, in order to allow for the right balance between performance, participant comfort and setup constraints. The table height was then elevated to the elbow to suit each individual participant's height. A chinrest was used to ensure that the participant would limit his or her movements and to keep the distance between the eyes and the writing surface constant. This was particularly important during the calibration phase. The participant's position was set up to be as comfortable as possible.

An image displayed on the tablet showed the eight pictures and delimited the writing area. The writing area consisted of two 12-lines columns. The button depicting the words 'EINDE' (i.e., "END") at the right bottom side of the writing area enabled the subject to end the task after finishing the writing assignment. Figure 5.1 shows the task environment with the information displayed on the screen during composition.

\section{Procedure}

After the eye-tracker had been installed and the calibration had been completed successfully, the composition task was carried out. For this task, instructions were both displayed on the 
screen and orally explained by the investigator. For the fifth graders, however, the investigator carefully explained the instructions, but the instructions on the screen were reduced to a minimum, to avoid distracting the fifth graders during explanation of the instructions.

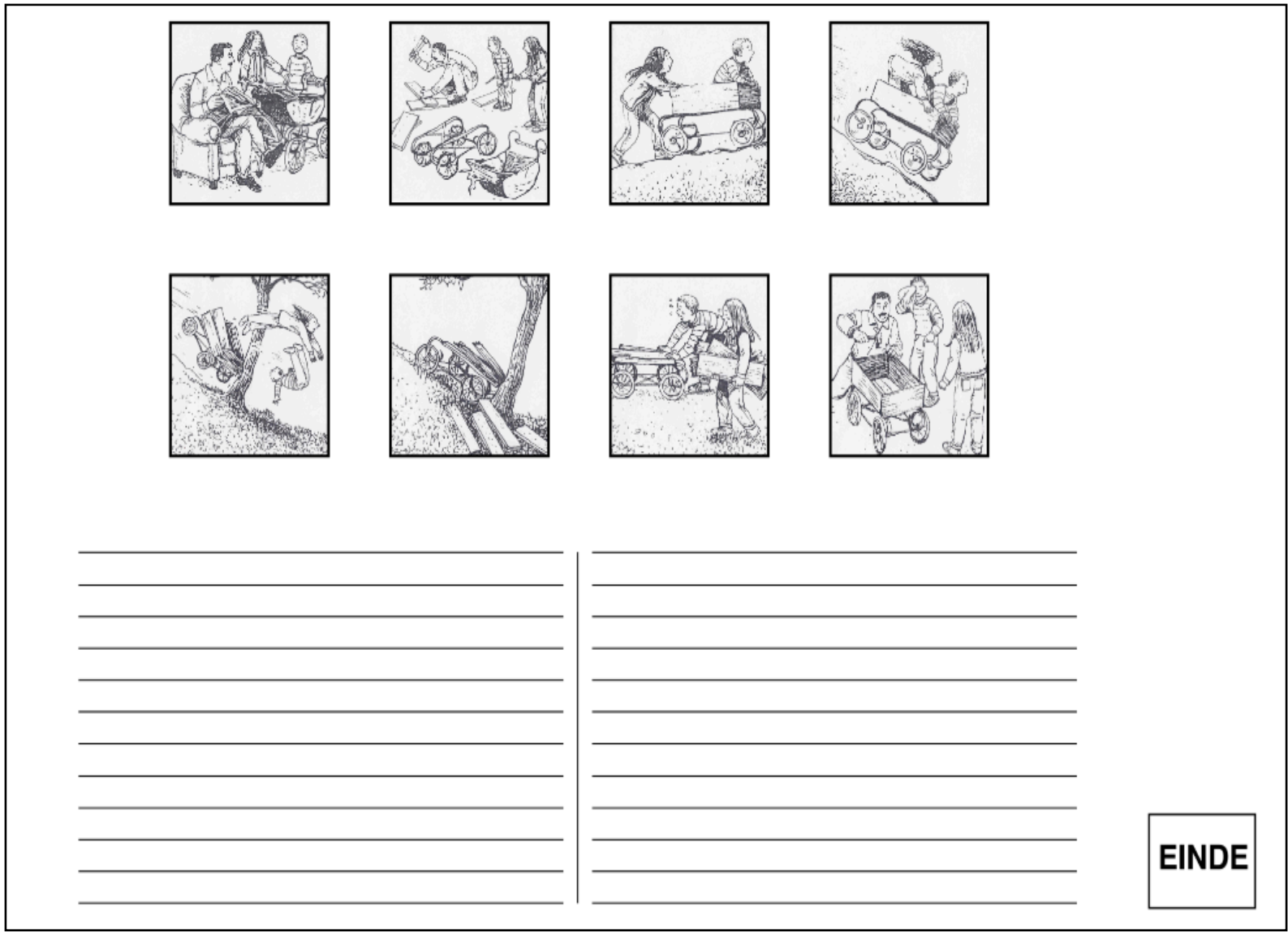

Figure 5.1 The task environment with the information displayed on the screen during composition.

\section{Measures}

Once the texts had been composed, two sets of variables were analyzed: 1) on-line process measures, derived from the analysis of handwriting activity and eye movements, and 2) offline product measures, resulting from an analytic scoring of the text quality of the written product. 


\section{On-line process measures}

General temporal parameters and handwriting activity. Three measures related to the general temporal parameters of the compositions were obtained, namely compositional fluency (in words per minute, wpm), mean pause duration (in milliseconds), and pause frequency (in number of pauses per minute, ppm). Note that all pauses lasted longer than a predetermined threshold of $35 \mathrm{~ms}$. This threshold is the result of a methodological criterion, which determines that a pause is at least equivalent to three successive digital samples (i.e., relative to the sampling frequency of the digitizing tablet) (see Alamargot et al., 2010 and Prunty, Barnett, Wilmut, \& Plumb, 2014 for further details). These general temporal parameters provided an overview of the temporal characteristics of the written trace of both groups of writers, and on how they differ. More specifically, undergraduate students wrote more fluently throughout composition than fifth graders (Undergraduate students: $M=20.90$; $S D=3.69$; Fifth graders: $M=12.72 ; S D=3.08 ; t(70)=10.15, p<.01 ; d=2.41)$. Mean pause duration was significantly higher for fifth graders than for undergraduate students (Undergraduate tudents: $M=398 ; S D=122$; Fifth graders: $M=796 ; S D=270 ; t(70)=-7.90$, $p<.01 ; d=-1.90)$, but undergraduate students paused significantly more often per minute than fifth graders (Undergraduate students: $M=73.05 ; S D=16.21$; Fifth graders: $M=37.99$; $S D=13.47 ; t(70)=10.02, p<.01 ; d=2.35)$.

Eye movements. General temporal parameters, and pauses in particular, were used in combination with eye movements to distinguish between three time frames of the writing process: prewriting, moments of sequential processing, and moments of parallel processing. Prewriting was defined as the time that elapses between the appearance of the image on the tablet and the setting of pen to paper. In order to pinpoint parallel processing, and distinguish it from sequential processing, two criteria were established: 1) the distance between the point of fixation on the source, and the point of inscription had to be greater than $4 \mathrm{~cm}$, to ensure that the latter was not in the parafoveal field of vision (Alamargot et al., 2007), 2) visual activity on the source, or from the text to the source had to occur during pauses whose duration was determined according to a relative pause threshold. Such a relative pause threshold was preferred over an absolute pause threshold, as it takes individual differences and group differences in handwriting skills into account. Establishing this relative threshold involved appealing to the categorization of pauses into quartiles according to their duration. 
Following Alamargot et al. (2010), the two quartiles with the lowest pause durations (Q1 and Q2) were considered to reflect handwriting pauses and thus handwriting. More particularly, pauses below this threshold correspond, for example, to the transcription of a dot on the "i". Hence, eye movements occurring during Q1 and Q2 pauses are defined as those involved in a phase of visual processing occurring parallel to handwriting. Consequently, eye movements occurring during Q3 and Q4 pauses are defined as visual processing occurring during a sequential period processing, i.e. during a large handwriting pause. (Alamargot et al., 2010; Prunty et al., 2014).

Fixations and gaze transitions served as the basis for four eye movement measures capturing the frequency and density of source consultation within these three different time frames. A fixation is defined as a position at which the eye stops for at least $50 \mathrm{~ms}$ in order to process information. A gaze transition is defined as the eye shifting from one fixation to the next (i.e. saccade), whereby no information is processed.

Frequency of source consultation was determined by analyzing the number of gaze transitions from text to source, which is thought to reflect the frequency with which the writer consults the source for information uptake (Alamargot, Chesnet, \& Caporossi, 2012). Note that for the prewriting phase, this measure was not calculated, as by definition prewriting does not involve any transition from text to source.

Density of source consultation was determined by analyzing the number of fixations on images, the number of gaze transitions between images, and the total gaze duration (in milliseconds). Building further on research on eye movements in reading, these measures were interpreted to reflect respectively the amount of information processed, the attempts to establish links between chunks of information depicted in different images, and the cognitive effort associated with it (e.g., Orrantia, Munez, \& Tarin, 2014; Torrance et al., 2015).

Besides these eye movement measures, two additional measures were calculated: for the prewriting phase, a general temporal parameter, namely prewriting duration (in milliseconds) was obtained. Moreover, a general indicator of amount of parallel processing was obtained, by calculating the percentage of composition time during which handwriting is continued with the eyes fixated on the source. 


\section{Off-line product measures}

A possible approach to the assessment of writing quality is through the analysis of linguistic features at distinct levels of written language. Frequently recurring features include measures of productivity (e.g., text length), complexity (e.g., syntactic complexity), and macro-organization (e.g., structure or content; Puranik, Lombardino, \& Altmann, 2008; Wagner et al., 2011). Unlike holistic ratings, these features concern characteristics that can be quantitatively measured (Crossley, Weston, McLain Sullivan, \& McNamara, 2011).

Moreover, such an analytic scoring method is convergent with the idea that writing is a multidimensional construct, and that writers can differ within themselves in their ability to produce text at the word-, sentence-, or text-level (Wagner et al., 2011; Whitaker, Berninger, Johnson, \& Swanson, 1994).

Text length. At the word-level, a measure of text length in number of words was obtained.

Syntactic complexity. At the sentence-level, the mean length of a t-unit in words was taken as a measure of syntactic complexity. A t-unit is defined as a main clause with all subordinate clauses associated with it (Hunt, 1966). Both text length and syntactic complexity were calculated using Computerized Language ANalysis (CLAN) software (MacWhinney, 2000).

Story ideas and story structure. At the text-level, two macrostructural measures were obtained: story ideas and story structure. Story ideas were scored following the standard procedures of the TAK task (Verhoeven \& Vermeer, 2001). The TAK task contains a list of nine main ideas that are represented in the story. One point was awarded for each idea included in the narrative. Raw scores were used in the analyses (maximum $=9$ ). Inter-rater reliability for this task is reported as .90 (Verhoeven \& Vermeer, 2001). The story structure was evaluated by scoring the presence of the narrative categories of setting, initiating event, internal response, attempts, direct consequence, and reaction (Stein \& Trabasso, 1982). Two points were awarded if the narrative category was described sufficiently; one point was awarded if the narrative category was only partially represented. This analysis of story structure provides a measure of the extent to which the writer infers the causal relationships between events in the story instead of simply describing the pictures as a series of unrelated events (Norbury \& Bishop, 2003). Raw scores were used in the analyses (maximum =12). All stories were rated separately by two raters on story ideas and story structure, and inter-rater reliability was good (Pearson $r=.89$ and Pearson $r=.88$ respectively). 


\section{Results}

\section{On-line Management of Written Composition}

Table 1 presents the differences between fifth graders and undergraduate students concerning the frequency and density of source consultation in the different time frames of the writing process. The alpha level was reduced by conducting Bonferroni corrections (set to .0125).

Prewriting. Regarding prewriting, results revealed that undergraduate students made marginally, but not significantly, more transitions between images in the source than fifth graders $(t(70)=2.07, p<.05 ; d=.49)$. While undergraduate students and fifth graders made similar number of fixations on images $(t(70)=1.70, p=.09 d=.39)$, on average undergraduate students looked significantly longer at images than fifth graders, as evidenced by the total gaze duration $(\mathrm{t}(70)=2.92, p<.0125 ; d=.69)$. Overall, our measure of prewriting duration indicated that undergraduate students spent significantly more time on prewriting than fifth graders (Undergraduate students: $M=33607$; $S D=17137$; Fifth graders: $M=21953 ; S D=20614 ; t(70)=2.62, p<.0125 ; d=.59)$.

Sequential processing. Opposite to our predictions, undergraduate students' dense source consultation during prewriting was not continued during episodes of sequential processing: instead, fifth graders demonstrated a more dense visual activity on the source than undergraduate students, as demonstrated by the number of fixations on images $(t(70)=-3.54$, $p<.0125, d=-.85)$, the number of transitions between images $(t(70)=-3.03, p<.0125, d=-$ $.72)$, and the total gaze duration $(t(70)=-3.05, p<.0125, d=-.71)$. Regarding frequency of source consultation, no difference was found between fifth graders and undergraduate students in the number of transitions from text to source $(t(70)=.47, p=.64, d=.11)$.

Parallel processing. First of all, the general indicator of parallel processing showed that undergraduate students dedicated a marginally, but not significantly, larger percentage of their composition time to parallel processing than fifth graders (Undergraduate students: $M=1.10$; $S D=1.22$; Fifth graders: $M=.62 ; S D=.57 ; t(70)=2.17, p<.05 ; d=.50)$. Looking more into depth into the eye movements in these episodes of parallel processing, undergraduate students made a higher number of fixations on the source than fifth graders $(t(70)=2.78, p<$ $.0125 ; d=.65)$, and a marginally higher number of transitions between images $(t(70)=1.88, p$ $=.065 ; d=.46)$. Also, undergraduate students' total gaze duration on the source tended to be slightly longer than fifth graders' total gaze duration $(t(70)=1.82, p=.073 ; d=.43)$. 
Regarding frequency of source consultation, again no differences were found between fifth graders and undergraduate students in terms of the number of transitions from text to source $(t(70)=1.04, p=.30, d=.24)$ 
Table 1

Means (SD) of Frequency and Density of Source Consultation during Prewriting, Sequential Processing, and Parallel Processing According to Level of Expertise

\begin{tabular}{|c|c|c|c|c|c|c|c|}
\hline & & \multicolumn{2}{|c|}{ During prewriting } & \multicolumn{2}{|c|}{ During sequential processing } & \multicolumn{2}{|c|}{ During parallel processing } \\
\hline & & 5 th graders & Students & 5 th graders & Students & 5 th graders & Students \\
\hline & & Mean (SD) & Mean (SD) & Mean $(S D)$ & Mean $(S D)$ & Mean $(S D)$ & Mean (SD) \\
\hline Frequency & Transitions text-source & - & - & $20.00(12.93)$ & $21.34(11.42)$ & $1.44(1.71)$ & $1.84(1.57)$ \\
\hline \multirow[t]{3}{*}{ Density } & Fixations on images & $46.03(44.94)$ & $61.55(32.90)$ & $120.18(78.39)$ & $66.95(41.71)$ & $7.88(6.94)$ & $15.16(14.37)$ \\
\hline & Transitions images & $17.24(16.03)$ & $25.24(16.70)$ & $36.29(27.59)$ & $19.74(16.78)$ & $1.26(1.56)$ & $2.21(2.62)$ \\
\hline & Total gaze duration & $16553(18038)$ & $27917(14963)$ & $35404(22530)$ & $21908(14495)$ & $2696(2295)$ & $3893(3254)$ \\
\hline
\end{tabular}

Note. Transitions text-source $=$ number of transitions from text to source. Fixations on images $=$ number of fixations on images. Transitions images $=$ number of transitions between images. Total gaze duration = total gaze duration on images in milliseconds. 


\section{The Relationship between On-line Management and Text Quality}

Table 2 presents fifth graders' and students' compositional performance on the different measures of text quality. A Bonferroni correction was used because of multiple tests (set to $.0125)$. Analyses showed that students wrote significantly longer $(t(70)=5.28, p<.0125 ; d=$ $1.26)$, and syntactically more complex $(t(70)=4.72, p<.0125 ; d=1.10)$ texts than fifth graders. Furthermore, students included significantly more story ideas $(t(70)=4.07, p<.01$; $d=.97)$ and more narrative categories of story structure $(t(70)=2.89, p<.0125 ; d=.68)$ in their stories compared to fifth graders.

Table 2

Means (SD) of Compositional Performance on Word-, Sentence-, and Text-Level of Text Quality According to Level of Expertise

\begin{tabular}{lrr}
\hline & 5th graders & Students \\
\hline & Mean $(S D)$ & Mean $(S D)$ \\
\hline Text length (N words) & $80.15(29.26)$ & $123.61(39.22)$ \\
Syntactic complexity & $5.25(0.88)$ & $6.35(1.10)$ \\
Story ideas & $6.15(1.71)$ & $7.55(1.13)$ \\
Story structure & $10.12(2.90)$ & $11.82(1.93)$ \\
\hline
\end{tabular}

For the calculation of the correlations between the characteristics of on-line management and text quality, a composite score for density of source consultation during prewriting, during sequential processing, and during parallel processing was computed. Composite scores allow for a more clear delineation of the relationships between the main variables. Based on conceptual relationships and high correlations between variables, the composite scores were computed by adding and averaging the z-scores of prewriting duration, number of fixations, number of transitions between images, and total gaze duration for the prewriting phase, and by adding and averaging the z-scores of number of fixations, number of transitions between images, and total gaze duration for the episodes of parallel and sequential processing.

The correlation coefficients in Table 3 illustrate the relationships between the characteristics of on-line management and text quality. A Bonferroni correction was used because of multiple tests (set to .01). For fifth graders, text length correlated significantly with frequency of source consultation during sequential processing. A nearly significant correlation was found between syntactic complexity and density of source consultation during prewriting 
$(p=.06)$. No correlations were found between characteristics of on-line management and story ideas or story structure. For students, text length correlated significantly with frequency and density of source consultation during sequential processing. Furthermore, syntactic complexity correlated significantly with density of source consultation during prewriting. Story ideas correlated positively with frequency of source consultation during parallel processing.

\section{Discussion}

In the present study, we sought to portray the on-line management of text production composition by fifth graders and undergraduate students, and to explore its relationship with the text quality of the written product. Studying eye movements within the imaged source, relative to three different time frames of the writing process enabled us to identify the extent to which writers implement low-level writing processes and high-level text elaboration processes sequentially or in parallel, and to describe in more detail how these high-level writing processes operate within the task environment during different time frames. 
Table 3

Pearson Correlation Coefficients between Characteristics of On-line Management and Text Quality According to Level of Expertise

\begin{tabular}{|c|c|c|c|c|c|c|c|c|}
\hline & & \multicolumn{2}{|c|}{ Text length } & \multicolumn{2}{|c|}{ Syntactic complexity } & \multicolumn{2}{|c|}{ Story ideas } & Story str \\
\hline Time frames & Characteristics & $5^{\text {th }}$ graders & Students & $5^{\text {th }}$ graders & Students & $5^{\text {th }}$ graders & Students & $5^{\text {th }}$ graders \\
\hline Prewriting & Prewriting density & -.09 & .08 & $.33^{\#}$ & $.50^{*}$ & -.02 & -.16 & -.08 \\
\hline Sequential processing & Sequential frequency & $.43^{\#}$ & $.62^{*}$ & -.05 & .07 & -.20 & .16 & -.30 \\
\hline & Sequential density & .15 & $.43^{*}$ & .01 & .08 & -.11 & -.13 & -.18 \\
\hline Parallel processing & $\%$ Parallel processing & .04 & -.26 & -.15 & -.02 & -.32 & .02 & -.18 \\
\hline & Parallel frequency & .24 & .30 & .12 & -.21 & .02 & $.34^{\#}$ & -.05 \\
\hline & Parallel density & .31 & -.03 & .06 & -.07 & -.27 & .24 & -.15 \\
\hline
\end{tabular}

Note. ${ }^{\#} \mathrm{p}<.10 .{ }^{*} \mathrm{p}<.01 . \%$ Parallel processing $=\%$ of composition time dedicated to parallel processing. Prewriting density $=$ density of source consultation during prewriting. Parallel frequency $=$ frequency of source consultation during parallel processing. Parallel density $=$ density of source consultation during parallel processing. Sequential frequency $=$ frequency of source consultation during sequential processing. Sequential density $=$ density of source consultation during sequential processing. 


\section{On-line Management of Written Composition}

With regards to the on-line management of written composition, first of all, results showed that students engaged slightly (but not significantly) more in parallel processing than fifth graders. Put simply, students tended to spend more time looking at the source while continuing handwriting than fifth graders. By providing a precise temporal indicator of parallel processing, this study both replicates and extends previous findings (i.e., Olive \& Kellogg, 2002; Chanquoy et al., 1990; Alamargot et al., 2010). Importantly, compared to the third graders in the study by Olive and Kellogg (2002), fifth graders did exhibit some episodes of parallel processing. As transcription skills are thought to gradually automatize in the upper elementary grades (Berninger \& Swanson, 1994), this may be interpreted as evidence that transcription skills in fifth graders are sufficiently automatized as to enable on some occasions the parallel execution of high-level text elaboration processes. Yet, their lower density of source consultation suggests that source consultation during handwriting consists of very quick glances, presumably because accumulated demands of different processes do not allow for more complex processing of the source. In this respect, it is possible that it is too costly for fifth graders to leave their written text: consulting the source extensively while brings along the risk of forgetting already developed ideas, as due to slow handwriting the writer cannot keep up with the speed at which language is generated in the mind (Limpo, Parente, \& Alves, 2018). As formulating, involving grammatical and lexical processing, is acquired prior to planning and reviewing (Berninger \& Swanson, 1994), and is also the least cognitively demanding writing process (Alves et al., 2008), it is conceivable that this is the process underlying source consultation that will run most often in parallel with handwriting both in fifth graders and in undergraduate students. Two considerations are worth noticing here. First, it is important to emphasize that in both groups of writers parallel processing represented only a very small percentage of the total composition time. Second, text elaboration processes can also take place on the basis of the text produced so far, or on the basis of an internal source, i.e. through the processing of knowledge stored in LTM. This implies that the actual percentage of composition time dedicated to parallel processing might be larger than reported here. For instance, given the high frequency of short pauses in undergraduate students, it is likely that other writing processes such as language preparation occur in parallel with handwriting, and as such alter the rhythm of handwriting (Chanquoy et al., 1990). 
Periods of pen inactivity, whether that is during prewriting, or during episodes of sequential processing, remained clearly the most important locations of high-level text elaboration processes. An in-depth exploration of the frequency and density of source consultation during prewriting and during episodes of sequential processing revealed further differences between fifth graders and undergraduate students. In line with developmental models of writing (Bereiter \& Scardamalia, 1987; Berninger \& Swanson, 1994), previous online studies have attested that with age and expertise, writers start to spend more time generating and organizing ideas prior to writing (e.g., Alamargot et al., 2010; Beauvais et al., 2012; Chanquoy et al., 1990). The longer prewriting duration of students compared to fifth graders in the present study confirms this finding. Furthermore, through the analysis of eye movements on the source, the present study was able to demonstrate that prewriting in more proficient writers is not only longer, but also entails a more dense observation of the source. As density of eye fixations represents a higher level of focused attention, and thus a higher level of cognitive processing (Shojaeizadeh, Djamasbi, \& Trapp, 2016), it could be that undergraduate students processed the information represented in the images more deeply. While this is entirely convergent with assumptions by Bereiter and Scardamalia (1987) and Berninger and Swanson (1994), stating that writing expertise is associated with more global text elaboration prior to writing, this study is one of the first to provide empirical support using real-time indicators for this claim (but see Alamargot et al., 2010).

During episodes of sequential processing, the main difference between the two groups of writers concerned the density of source consultation, showing that students engaged in a less dense source consultation than fifth graders, and this during pauses that were significantly shorter than fifth graders' pauses. During pauses, students did return as frequently to the source as fifth graders. In a capacity view of writing (McCutchen, 1996), it could be said that students' prewriting activity lessened the cognitive cost of text elaboration processes during composition (Beauvais et al., 2012), thereby reducing the need for long pauses to reflect over the images. The finding that students returned as frequently to the source as fifth graders is not necessarily inconsistent with this interpretation. More specifically, a possible consequence of the prewriting activity and the proceduralized narrative genre in students is that it not only enabled them to more quickly uptake information during pauses, but also to consult the source for cognitively less demanding sub-processes of text elaboration, such as to guide linguistic formulation processes. Indeed, the fact that, overall, students made very frequent, albeit short, pauses, suggests that students' writing process does proceed in a somehow fragmented, 
sequentialized way, similar to the step-by-step composing characteristic of knowledge-telling (Bereiter \& Scardamalia, 1987). These results resemble findings reported by Beauvais et al. (2011), who found students to alternate frequently between short episodes of formulating and planning during narrative composition - in their case a marker of skilled composition (Olive, 2014). Our results suggest that these alternations are embedded in varying patterns of handwriting and short pauses. In addition, as previously mentioned, frequent, short pauses may also indicate that several writing processes run in parallel, and that the rhythm of writing slows down to accommodate these processes (Chanquoy et al., 1990).

Turning to the fifth grader, instead, the less dense visual activity on the source prior to writing provides an explanation for why fifth graders have to use longer pauses during composition to grasp all the information depicted in the source. Hence, in line with capacity theory (McCutchen, 1996), the limited source consultation during prewriting postpones major text elaboration processes to the composition phase, increasing the amount of cognitive resources necessary for their implementation. In this respect, the longer pauses in fifth graders presumably result from the accumulated demands of different writing processes. Whereas the student consults the source for information uptake, and immediately proceeds to transcribing the information while simultaneously thinking about how to convert the information into linguistic material (Alves et al., 2008; McCutchen, 1996), the fifth grader is forced to devote execution periods exclusively to handwriting, and pauses to high-level writing processes, including both conceptual processing of information in the source and preparation of the linguistic formulation of this information. The overall result is a sequentialized step-by-step writing process, which alternates longer pauses with execution periods. The fact that fifth graders did explore the source densily during the pauses, different from the $7^{\text {th }}$ grader in the study by Alamargot et al. (2010) and opposite to our predictions, could indicate that the task at hand, providing a clearly delineated amount of information, more easily invites the young writer to process all information extensively as opposed to a task with a documentary source as in Alamargot et al. (2010). Furthermore, the narrative story used in the present study is more simple in nature than the novel-based incipit that students had to extend in the study by Alamargot et al. (2010).

Taken together, several key differences characterize the strategies that fifth graders and undergraduate students use to manage written composition on-line. A similarity between both groups of writers is the fragmented, sequentialized writing process, which confirms that in the case of simple, narrative tasks, a step-by-step way of composing, likened to the knowledge- 
telling strategy (Bereiter \& Scardamalia, 1987), is commonly used by writers, irrespective of their level of expertise. Importantly, however, the sequentialization manifests itself differently in terms of pause duration and characteristics of source consultation, suggesting that it is governed by different purposes and constraints.

\section{Relationship between On-line Management and Text Quality}

In general, undergraduate students outperformed fifth graders on all measures of text quality. For obvious reasons, a different degree of linguistic proficiency is probably a prime factor in explaining these differences in text quality. Nevertheless, with low-level writing processes still being highly demanding, it is also possible that fewer resources will be available to linguistically and conceptually elaborate their texts (Berninger \& Winn, 2006; Olive et al., 2009). The way writers manage writing processes on-line has been put forward as a decisive factor for text quality (e.g., Breetvelt et al., 1994; Levy \& Ransdell, 1995). In the present study, characteristics of on-line management were found to be related to the wordlevel, i.e. the text length of the narratives. For undergraduate students, engaging in more frequent and dense source consultation during sequential processing also led to longer texts. As this beneficial effect was not observed for the sentence- or text-level of the narrative, it seems reasonable to conclude that in undergraduate students, more frequent and dense source consultation during pauses served predominantly to support linguistic formulation processes that advanced the length of texts. It might, for instance, be that during pauses students looked at the source to capture information that did not affect the plot of the story, but that added details to the story, leading to longer texts. While it goes beyond the scope of the present study, a more fine-grained analyis of gaze behaviour could be informative in this respect. For now it suffices to say that this interpretation is convergent with the assumptions about their on-line management as outlined above.

At the sentence-level, syntactic complexity of the narratives was found to be significantly and nearly significantly related to density of source consultation during prewriting in students and fifth graders, respectively. This emphasizes that producing well-structured sentences depends on the ability to take the time before writing to plan the text to come (Beauvais et al., 2011). This should not straightforwardly be interpreted as evidence for the idea that good writers plan the syntax of their texts before writing it down. Instead, in the framework of capacity theory (McCutchen, 1996), it is possible that the more the content is planned prior to writing, the more cognitive resources are available during writing to dedicate to the packaging of content into syntactically complex units. 
Taken together, it can be concluded that in fifth graders only few relationships between online management and text quality were encountered. In students, by contrast, slightly more relations were found. These findings thus suggest that with age, on-line management as measured in the present study becomes more closely related to text quality. This fits with the idea that in the upper elementary grades, more complex and interactive processing, such as the engagement in planning prior to writing, does not necessarily guide text generation yet (Berninger \& Swanson, 1994). In novice writers, strategies are thus mostly an implicit consequence of trying to cope with the cognitive demands of writing, rather than the result of an explicit, self-regulative decision implemented in order to improve text quality.

\section{Limitations and future directions}

It is important to raise some limitations of this study that could reduce the scope of our findings. First, in the present study a highly controlled experimental design using a visual source of images was used to single out high-level text elaboration processes. We did not, however, distinguish between different sub-processes of text elaboration that may drive source consultation, such as planning the content, verifying the content of the text produced so far with the information available in the source, and prompting lexical retrieval (Alamargot, Chanquoy, \& Chuy, 2005). Considering that a high-level writing process can have a different function throughout the writing task, and accordingly, have a varying relationship with text quality (e.g., Breetvelt et al., 1994), it might be important to more clearly delineate the functions that high-level text elaboration processes fulfill throughout the writing task. This may be helpful to substantiate our interpretations of the writers' on-line management, and to study the relationships with text quality into more depth. A more detailed analysis that links the eye movements on the source to the immediately following writing performance in the text produced so far may be informative in this respect. Relatedly, although our task rendered text elaboration highly dependent on source consultation, we certainly did not capture all moments where writers engaged in text elaboration. More particularly, a writer may also use the text produced so far as an external source in order to elaborate and create new content (Alamargot et al., 2010) or he may stare at the blank page when he is carrying out complex thinking processes (Alamargot et al., 2006). Future studies could therefore include eye movements on the text produced so far and gaze aversions while studying the on-line management of written composition (De Smedt, Leijten, \& Van Waes, 
2018; Johansson et al., 2010; Nottbusch, 2010; Torrance \& Nottbusch, 2012; Torrance et al. 2015). A second limitation relates to the writing task and genre used in the present study. The prompt consisting of a sequence of images may have enhanced fifth graders' sequentialized writing strategy. More specifically, illustrations have been found to have a load-adding effect (Mayer, Heiser, \& Lonn, 2001), especially for people with limited WM capacity (Orrantia, Munez, \& Tarin, 2014). For fifth graders, whose WM is already more susceptible to a cognitive overload due to the dynamic interaction of the different demanding writing processes, this task may have constrained, not facilitated, narrative composition, and may have partly determined their on-line management of the writing process. Moreover, although we carefully piloted the administration of the writing task, in particular with regard to the participants' exigencies and comfort, it is plausible that the limited number of lines for writing, and the experimental conditions with heavy eye-tracking equipment have disencouraged students to implement high-level processes, such as rereading and revising texts. This might have led to a more step-by-step way of writing.

Furthermore, for narrative writing, the cognitive load is significantly lower than for writing argumentative texts (Olive, Favart, Beauvais, \& Beauvais, 2009; Kellogg, 2001). Relatedly, writing tasks that do not include an external prompt to assist with content generation may require the writer to use more sophisticated and explicit writing strategies (Burtis, Bereiter, Scardamalia, \& Tetroe, 1983; Grabowski, 1996). Hence, future studies could investigate online management of more complex genres in more ecologically valid writing tasks using different sources, and explore its impact on text quality.

A final limitation of the study is that we adopted a novice/expert paradigm. There are at least two drawbacks of this choice. First of all, this paradigm allowed us to describe two developmentally different approaches to the management of writing processes, but does not give any hint on when and how writers move from one stage to the other. Further crosssectional research, covering a wider range of age groups, is needed to examine how the online management of written text production changes as children move into secondary school and beyond. Second, interindividual differences within groups of writers were not explored. However, both novices and more expert writers can be defined in many ways (Torrance, 1996). Hayes (2011), for instance, has proposed that the knowledge-telling strategy for expository writing in children can be divided into different subcategories, accounting for both developmental and interindividual differences. As such, fifth graders' narrative writing strategies as evidenced in the present study could also be clustered into sub-groups on the 
basis of the characteristics of on-line management. Hence, the results of the present study could be taken a step further, by investigating variance in on-line management of written composition, and by identifying the factors that are most heavily implicated in compromising this on-line management. Degree of handwriting automatization (e.g., Olive \& Kellogg, 2002) and WM capacity (Alamargot et al., 2011), particularly visual WM (Olive \& Passerault, 2012), are likely sources of individual differences, but also executive functions may mediate writing process management (Olive, 2014).

In conclusion, in this study we were able to document and compare differences in the online management of written composition between fifth graders and undergraduate students through a very fine-grained methodological paradigm of handwriting activity and eye movements. Not only did this methodological approach allow us to pinpoint sequential and parallel processes, it also provided novel insight in the way writing processes interact within the task environment. The strictly controlled experimental design entailed some limitations, which may have compromised the relationship with text quality, and which raise new questions regarding generalization of findings to other writing tasks. Yet, the proven feasibility of the methodology for investigating text production in writers of different ages, and the wealth of data generated by it, provide ample possibilities for future research to further explore the on-line management of written composition in writers with different levels of expertise. 
Compliance with Ethical Standards:

Conflict of Interest: All authors declare that they have no conflict of interest.

Ethical approval: All procedures performed in studies involving human participants were in accordance with the ethical standards of the institutional and/or national research committee and with the 1964 Helsinki declaration and its later amendments or comparable ethical standards.

Informed consent: Informed consent was obtained from all individual participants included in the study.

\section{References}

Alamargot, D., Chesnet, D., \& Caporossi, G. (2012). Using Eye and Pen Movements to Study the Writing Process. In M. Fayol, D. Alamargot \& V. W. Berninger (Eds.), Translation of Thought to Written Text While Composing: Advancing Theory, Knowledge, Research Methods, Tools, and Applications. Psychology Press. 
Alamargot, D., Chanquoy, L., \& Chuy, M. (2005). L'élaboration du contenu du texte: de la mémoire à long terme à l'environnement de la tâche [Text content elaboration: from long-term memory to task environment]. Psychologie Française, 50, 287-304.

Alamargot, D., Chesnet, D., Dansac, C., \& Ros, C. (2006). Eye and pen: A new device to study the reading during writing. Behavior Research Methods, Instruments and Computers, 38, 287-299. doi:10.3758/BF03192780

Parallel processing before and after pauses: A combined analysis of handwriting and eye movements during procedural text production. In M. Torrance, L. van Waes \& D. Galbraith (Eds.), Writing and cognition: Research and applications (pp. 13-29). Amsterdam, the Netherlands: Elsevier.

Alamargot, D., Plane, S., Lambert, E., \& Chesnet, D. (2010). Using eye and pen movements to trace the development of writing expertise: Case studies of a seventh, ninth and twelfth grader, graduate student, and professional writer. Reading and Writing: An Interdisciplinary Journal, 23, 853-888. doi:10.1007/s11145-009-9191-9

Alamargot, D., Caporossi, G., Chesnet, D., \& Ros, C. (2011). What makes a skilled writer? Working memory and audience awareness during text composition. Learning and individual differences, 21, 505-516. doi:10.1016/j.lindif.2011.06.001

Alamargot, D., Flouret, L., Larocque, D., Caporossi, G., Pontart, V., Paduraru, C., Morisset, P., \& Fayol, M. (2015). Successful written subject-verb agreement: an online analysis of the procedure used by students in grades 3, 5, and 12 . Reading and Writing: An Interdisciplinary Journal, 28, 291-312. doi:10.1007/s11145-014-9525-0

Alves, R. A., Castro, S. L., \& Olive, T. (2008). Execution and pauses in writing narratives: Processing time, cognitive effort and typing skill. International Journal of Psychology, 43, 969-979. doi:10.1080/00207590701398951

Alves, R. A., \& Limpo, T. (2015). Progress in written language bursts, pauses, transcription, and written composition across schooling. Scientific Studies of Reading, 19, 374-391.

Alves, R. A., Limpo, T., Fidalgo, R., Carvalhais, L., Pereira, L. A., Castro, S. L. (2016). The impact of promoting transcription on early text production: Effects on bursts and pauses, levels of written language, and writing performance. Journal of Educational Psychology, 108, 665-679.

Berninger, V. W., \& Swanson, H. L. (1994). Modifying Hayes and Flower'smodel of skilled writing to explain beginning and developing writing. In J. S. Carlson (Ed.) \& E. C. Butterfield (Vol. Ed.), Advances in cognition and educational practice, Vol.2: Children's writing: Toward a process theory of the development of skilled writing (pp. 57-81). Greenwich, CN: JAI Press.

Beauvais, L., Favart, M., Passerault, J. M., \& Beauvais, C. (2012). Temporal management of the writing process: effects of genre and organizing constraints in grade 5, 7, and 9. Written communication, 31, 251-279.

Beauvais, C., Olive, T., \& Passerault, J. M. (2011). Why some texts are good and others not? Relationship between text quality and management of the writing processes. Journal of Educational Psychology, 103, 415-428. doi: $10.1037 / \mathrm{a} 0022545$

Bereiter, C., \& Scardamalia, M. (1987). The psychology of written composition. Hillsdale, NJ: Lawrence Erlbaum.

Berninger, V. W., \& Winn, W. (2006). Implications of advancements in brain research and technology for writing development, writing instruction, and educational evolution. In C. MacArthur, S. Graham \& J. Fitzgerald (Eds.), Handbook of writing research (pp. 96-114). New York, NY: Guilford Press.

Braaksma, M. A. H., Rijlaarsdam, G., van den Bergh, H., \& Van Hout-Wolters, B. H. A. M. (2004). Observational learning and its effects on the orchestration of the writing process. Cognition and Instruction, 22, 1-36. doi:10.1207/s1532690Xci2201 1

Breetvelt, I., van den Bergh, H., \& Rijlaarsdam, G. (1994). Relations between writing processes and text quality: When and how? Cognition and instruction, 12, 103-123. doi:10.1207/s1532690xci1202_2

Burtis, J., Bereiter, C., Scardamalia, M., \& Tetroe, J. (1983). The development of planning in writing. In G. Wells \& B. Kroll (Eds.), Explorations in the development of writing (pp. 153-174). Chicester, Englsand: John Wiley.

Chanquoy, L., \& Alamargot, D. (2002). Mémoire de travail et rédaction de textes: Evolution des modèles et bilan des premiers travaux. L'année Psychologique, 102, 363-398. doi:10.3406/psy.2002.29596 
Chanquoy, L., Foulin, J. N., \& Fayol, M. (1990). The on-line management of short text writing by children and adults. European Bulletin of Cognitive Psychology, 10, 513-540.

Chesnet, D., \& Alamargot, D. (2005). Analyses en temps réel des activités oculaires et graphomotrices du scripteur: intérêt du dispositif 'Eye and Pen'. L'Année Psychologique, 105, 477-520. doi:10.3406/psy.2005.29706

De Smedt, M., Leijten, M., \& Van Waes, L. (2018). Exploring the Process of Reading during Writing Using Eye Tracking and Keystroke Logging. Written Communication, 35(4), 411-447. doi:10.1177/0741088318788070.

Fayol, M. (1999). From on-line management problems to strategies in written composition. In M. Torrance \& G. Jeffery (Eds.), The cognitive demands of writing: Processing capacity and working memory effects (pp. 13-23). Amsterdam, the Netherlands: Amsterdam University Press.

Galbraith, D., \& Rijlaarsdam, G. (1999). Effective strategies for the teaching and learning of writing. Learning and Instruction, 9, 93-108. doi:10.1016/S0959-4752(98)00039-5

Grabowski, J. (1996). Writing and speaking: Common grounds and differences toward a regulation theory of written language production. In C. M. Levy \& S. Ransdell (Hrsg.), The science of writing: Theories, methods, individual differences, and applications (pp. 73-91). Mahwah, NJ: Erlbaum.

Graham, S., Berninger, V., Abbott, R., Abbott, S., \& Whitaker, D. (1997). The role of mechanics in composing of elementary school students: A new methodological approach. Journal of Educational Psychology, 89, 170-182. doi:10.1037/00220663.89.1.170

Hayes, J. R. (2011). Kinds of Knowledge-Telling: Modeling Early Writing Development. Journal of Writing Research, 3, 7392. doi:10.17239/jowr-2011.03.02.1

Hunt, K. W. (1966). Sentence structures used by superior students in grades four and twelve, and by superior adults. CRP 5 0313. Tallahassee, FL: Florida State University.

Johansson, R., Wengelin, A., Johansson, V., Holmqvist, K., Wengelin, A., Johansson, V., \& Holmqvist, K. (2010). Looking at the keyboard or the monitor: relationship with text production processes. Reading and Writing: An Interdisciplinary Journal, 23, 835-851. doi:10.1007/s11145-009-9189-3.

Just, M. A., \& Carpenter, P. A. (1992). A capacity theory of comprehension: Individual differences in working memory. Psychological Review, 99, 122-149. doi:10.1037/0033-295X.99.1.122

Kellogg, R. T. (1986). Designing idea processors for document composition. Behavior Research Methods. Instruments, \& Computers, 18, 118-128. doi:10.3758/BF03201010

Kellogg, R. T. (1987). Effects of topic knowledge on the allocation of processing time and cognitive effort to writing processes. Memory \& Cognition, 15, 256-266. doi:10.3758/BF03197724

Kellogg, R. T. (2001). Competition for working memory among writing processes. American Journal of Psychology, 114, 175-191. doi: $10.2307 / 1423513$

Kellogg, R. T. (2008). Training writing skills: A cognitive developmental perspective. Journal of writing research, 1, 1-26. doi:10.17239/jowr-2008.01.01.1

Kieft, M., Rijlaarsdam, G., \& van den Bergh, H. (2008). An aptitude-treatment interaction approach to writing-to-learn. Learning and Instruction, 18, 379-390. doi:10.1016/j.learninstruc.2007.07.004

Lambert, E., Alamargot, D., Larocque, D., \& Caporossi, G. (2011). Dynamics of spelling process during a copy task: effects of regularity and frequency. Canadian Journal of Experimental Psychology, 65, 141-150. doi:10.1037/a0022538

Levy, C. M., \& Ransdell, S. E. (1995). Is writing as difficult as it seems?. Memory and Cognition, 23, 767-779. doi:10.3758/BF03200928

Levy, C. M., \& Ransdell, S. E. (1996). Writing signatures. In C. M. Levy \& S. E. Ransdell (Eds.), The science of writing. Theories, methods, individual differences and applications (pp. 149-161). Mahwah, NJ: Erlbaum.

Limpo, T., \& Alves, R.A. (2018). Tailoring multicomponent writing interventions Effects of handwriting fluency and spelling accuracy on writing performance via planning and translating in middle grades. Learning and Individual Differences, 53, 26-36. 
MacWhinney, B. (2000). The CHILDES Project: Tools for Analyzing Talk. Mahwah, NJ: Lawrence Erlbaum Associates.

Mayer, R. E., Heiser, J., \& Lonn, S. (2001). Cognitive constraints on multi-media learning: When presenting more material results in less understanding. Journal of Educational Psychology, 93, 187-198. doi:10.1037/0022-0663.93.1.187

McCutchen, D. (1988). "Functional automaticity" in children's writing: A problem of metacognitive control. Written Communication, 5, 306-324. doi:10.1177/0741088388005003003

McCutchen, D. (1996). A capacity theory of writing: Working memory in composition. Educational Psychology Review, 8 , 299-325. doi:10.1007/BF01464076

Norbury, C. F., \& Bishop, D. V. (2003). Narrative skills of children with communication impairments. International Journal of Language and Communication Disorders, 38, 287-313. doi:10.1080/136820310000108133

Nottbusch, G. (2010). Grammatical planning, execution, and control in written sentence production. Reading and writing: an interdisciplinary journal, 23, 777-801. doi:10.1007/s11145-009-9188-4

Olive, T. (2014). Toward a parallel and cascading model of the writing system: A review of research on writing processes coordination. Journal of Writing Research, 6, 141-171. doi:10.17239/jowr-2014.06.02.4

Olive, T., Alves, R. A., \& Castro, S. L. (2009). Cognitive processes in writing during pauses and execution periods. European Journal of Cognitive Psychology, 21, 758-785.

Olive, T., \& Cislaru, G. (2015). Linguistic forms at the process/product interface. Analysing the linguistic content of bursts of production. In Georgeta Cislaru (Ed.), Writing(s) at the crossroads: the process/product interface (pp. 99-123). Amsterdam - Philadelphia: John Benjamins.

Olive, T., Favart, M., Beauvais, C., \& Beauvais, L. (2009). Children's cognitive effort and fluency in writing: Effect of genre and of handwriting automatisation. Learning and Instruction, 19, 299-308. doi:10.1016/j.learninstruc.2008.05.005

Olive, T., \& Kellogg, R. T. (2002). Concurrent activation of high- and low-level production processes in written composition. Memory \& Cognition, 30, 594-600. doi:10.3758/BF03194960

Olive, T., Kellogg, R. T., \& Piolat, A. (2001). The triple-task technique for studying the process of writing. In T. Olive \& C. M. Levy (Eds), Contemporary tools and techniques for studying writing (pp. 31-58). Dordrecht: Kluwer Academic Publishers.

Olive, T. \& Passerault, J.-M. (2012). The visuospatial dimension of writing. Written Communication, 29, 326-344. doi: $10.1177 / 0741088312451111$

Orrantia, J., Munez, D., \& Tarín, J. (2014). Connecting goals and actions during reading: the role of illustrations. Reading and Writing: An Interdisciplinary Journal, 27, 153-170. doi:10.1007/s11145-013-9437-4

Piolat, A., \& Olive, T. (2000). Comment étudier le coûte et le déroulement de la rédaction de textes? La méthode de tripletâche: un bilan méthodologique. L'Année Psychologique, 100, 465-502. doi:10.3406/psy.2000.28655

Prunty, M. M., Barnett, A. L., Wilmut, K., Plumb, M. S. (2014). An examination of writing pauses in the handwriting of children with Developmental Coordination Disorder. Research in developmental disabilities, 35, 2894 - 2905. doi:10.1016/j.ridd.2014.07.033

Rijlaarsdam, G. \& van den Bergh, H. (1996). Essentials for writing process studies: many questions and some answers. In, M.C. Levy \& S. Ransdell (Eds.), The science of writing (pp. 107-126). New York, NY: Lawrence Erlbaum ass.

Shojaeizadeh, M., Djamasbi, S., \& Trapp, A. C. (2016, July). Density of Gaze Points Within a Fixation and Information Processing Behavior. In International Conference on Universal Access in Human-Computer Interaction (pp. 465-471). Springer International Publishing

Sita, J. C., \& Taylor, K. A. (2015). Eye movements during the handwriting of words: individually and within sentences. Human movement science. 43, 229-38. doi:10.1016/j.humov.2015.01.011

Stein, N. L., \& Trabasso, T. (1982). What's in a story: Critical issues in story comprehension. In R. Glaser (Ed.), Advances in the psychology of instruction (pp. 213-268). Hillsdale, NJ: Lawrence Erlbaum Associates. 
Torrance, M. (1996). Is writing expertise like other kinds of expertise? In G. Rijlaarsdam, H. van den Bergh \& M. Couzijn (Eds.), Theories, models and methodology in writing research (pp. 268-281). Amsterdam, the Netherlands: Amsterdam University Press.

Torrance, M., \& Nottbusch, G. (2012). Written production of single words and simple sentences. In V. Berninger (Ed.), Past, present, and future contributions of cognitive writing research to cognitive psychology (pp. 403-422). New York, NY: Taylor Francis.

Torrance, M., Johansson, R., Johansson, V., \& Wengelin, A. (2015). Reading during the composition of multi-sentence texts: an eye-movement study. Psychological Research, 1-15. doi:10.1007/s00426-015-0683-8

van den Bergh, H., \& Rijlaarsdam, G. (1999). The dynamics of idea generation during writing: An on-line study. In M. Torrance \& D. Galbraith (Eds.), Studies in writing. Vol. 4. Knowing what to write: Cognitive perspectives on conceptual processes in text production (pp. 99-120). Amsterdam, the Netherlands: Amsterdam University Press.

van den Bergh, H., \& Rijlaarsdam, G. (2001). Changes in cognitive activities during the writing process, and relations with text quality. Educational Psychology, 21, 373-385. doi:10.1080/01443410120090777

van den Bergh, H., \& Rijlaarsdam, G. (2007). The dynamics of idea generation during writing: an online study. In G. Rijlaarsdam (Series Ed.) and M. Torrance, L. van Waes \& D. Galbraith (Vol. Eds.), Studies in Writing Vol. 20, Writing and Cognition: Research and Applications (pp. 125-150). Amsterdam, the Netherlands: Elsevier.

van der Hoeven, J. (1997). Children's composing: A study into the relationship between writing processes, cognitive and linguistic skill and text quality. Amsterdam: Rodopi.

Van Galen, G. P. (1991). Handwriting: Issues for a psychomotor theory. Human Movement Science, 10, 165-191. doi: 10.1016/0167-9457(91)90003-G

Van Waes, L., Leijten, M., \& Quinlan, T. (2010). Reading during sentence composing and error correction: a multilevel analysis of the influences of task complexity. Reading and Writing: An Interdisciplinary Journal, 23, 803-834. doi:10.1007/s11145-009-9190-x.

Verhoeven, L., \& Vermeer, A. (2001). Taaltoets Alle Kinderen [TAK]. Arnhem: Cito groep.

von Koss Torkildsen, J., Morken, F., Helland, W.A., \& Helland, T. (2015). The dynamics of narrative writing in primary grade children: writing process factors predict story quality. Reading and Writing: An Interdisciplinary Journal, 29, 529554. doi:10.1007/s11145-015-9618-4

Wagner, R. K., Puranik, C. S., Foorman, B., Foster, E., Tschinkel, E., \& Kantor, P. T. (2011). Modeling the development of written language. Reading and Writing: An Interdisciplinary Journal, 24, 203-220. doi:10.1007/s11145-010-9266-7

Wengelin, A., Torrance, M., Holmqvist, K., Simpson, S., Galbraith, D., Johansson, V., \& Johansson, R. (2009). Combined eyetracking and keystroke-logging methods for studying cognitive processes in text production. Behavior Research Methods, 41, 337-351. doi:10.3758/BRM.41.2.337

Whitaker, D., Berninger, V. W., Johnston, J., \& Swanson, L. (1994). Intraindividual differences in levels of language in intermediate grade writers: Implications for the translating process. Learning and Individual Differences, 6, 107-130. doi:10.1016/1041-6080(94)90016-7 